\title{
Population Policy and Policy Measures
}

\author{
MARKKU LEHTO \\ Chief of Planning \\ Ministry of Social Affairs and Health
}

Fertility, mortality and migration are the well-known factors of quantitative population policy. These factors affect the development of population size. Consensus on the aims for these factors seems to vary, however. Much has been said about the high rate of mortality in Finland and there seems to be agreement that, in order to improve mortality development, active measures must be taken within health care and other areas of social development policy. The high rate of emigration has also been considered a problem. It seems much more difficult to determine aims for fertility, however. On the one hand, there is concern for the low birthrate and the decreasing number of Finns. On the other hand, the problem can be seen in a global framework, which leads to concern about the growth of the world population. No doubt the size of the population can be seen more as an instrumental value than as a value in itself. This means that determining what is favorable population development greatly depends on the aims one wishes to associate it with.

The main focus in discussing population policy measures is on fertility. The current level of fertility is not sufficient to maintain the existing number of Finns. This problem is not typical of Finland alone. Nordic comparisons show that Finland's birthrate at the end of the 70s was, in fact, slightly higher than in the other Nordic countries. On the other hand, it must also be noted that in the early 1970s Finland's birthrate went down to quite a low level (Table 1). The birthrate declined quite even-

T a b l e 1. The development of fertility in the Nordic Countries in 1951-1978. (age-specific fertility rates)

$\begin{array}{lcccc} & \text { Finland } & \text { Sweden } & \text { Norway } & \text { Denmark } \\ 1951-60 & 97.5 & 72.2 & 77.1 & 71.4 \\ 1961-70 & 80.2 & 74.1 & 77.7 & 70.3 \\ 1971-75 & 58.0 & 69.0 & 70.7 & 62.8 \\ 1978 & 59.6 & 56.7 & 57.2 & 51.7\end{array}$

The figures for Finland and Sweden have been calculated for 15-44 year old women, for Norway and Denmark'for 15-49 year old women.

Source: Statistical yearbooks of Finland, Sweden, Norway and Denmark. 
ly from the 1950 s up till 1973 . At this time a low point was reached, and thereafter fertility started to climb only to turn down again in the latter half of the decade. The age structure in Finland in regard to fertility has been exceptionally favorable. This is demonstrated by calculating what the birthrate would have been in 1978, if the female population of fertile age had given birth at the rate women did in previous years (Table 2).

T a b l e 2. Imputed fertility for 1978 , if fertility had corresponded to the general fertility figures of the said years.

\begin{tabular}{|c|c|c|c|}
\hline & General fertility & $\begin{array}{l}\text { Imputed fertility } \\
1978\end{array}$ & $\begin{array}{c}\text { The actual birthrate } \\
\text { of that year }\end{array}$ \\
\hline If the level for 1950 & 106.1 & 113951 & 98065 \\
\hline If the level for 1955 & 97.9 & 105145 & 89740 \\
\hline If the level for 1960 & 89.4 & 96016 & 82129 \\
\hline If the level for 1965 & 78.5 & 84309 & 77885 \\
\hline If the level for 1970 & 63.9 & 68629 & 64559 \\
\hline If the level for 1978 & 61.6 & & 63983 \\
\hline
\end{tabular}

In 1978 sligthly less than 64000 children were born. If fertility had corresponded to the level of 1950 , almost 114000 children would have been born. This would have been greater than the fertility which actually prevailed in 1950. In fact, in all the years used in comparison, the age structure of 1978 would have reached a higher fertility than actually was reached.

\section{The effect of family policy on fertility}

A declining birthrate is often explained by saying that not enough energy or resources have been expended on family policy. Here I will examine the development of fertility and of four different indicators measuring family policy income transfers from 1950 to 1978 (Figure 1). One factor dercribing income transfers is family policy expenditures as a percentage of social expenditures. The second factor is formed by family policy expenditures as a percentage of the gross national product. The third way to calculate the development of family policy is to relate family policy expenditures to the number of children, that is to figure out family policy expenditures per child under 16 years of age. The fourth factor is formed by family policy expenditures per child under 16 in relation to the gross domestic product at market prices per capita. Thus, this factor construction, which may seem somewhat complicated, tells us how family policy income transfers calculated per child correspond to the figure which describes the size of the gross national product per citizen. Roughly speaking you could say that we are comparing pay for children to actual working pay. 
F ig u r e 1. The development of general fertility and family policy social expenditures (Index: The year $1950=100$; in parentheses is the correlation with the general fertility figure).

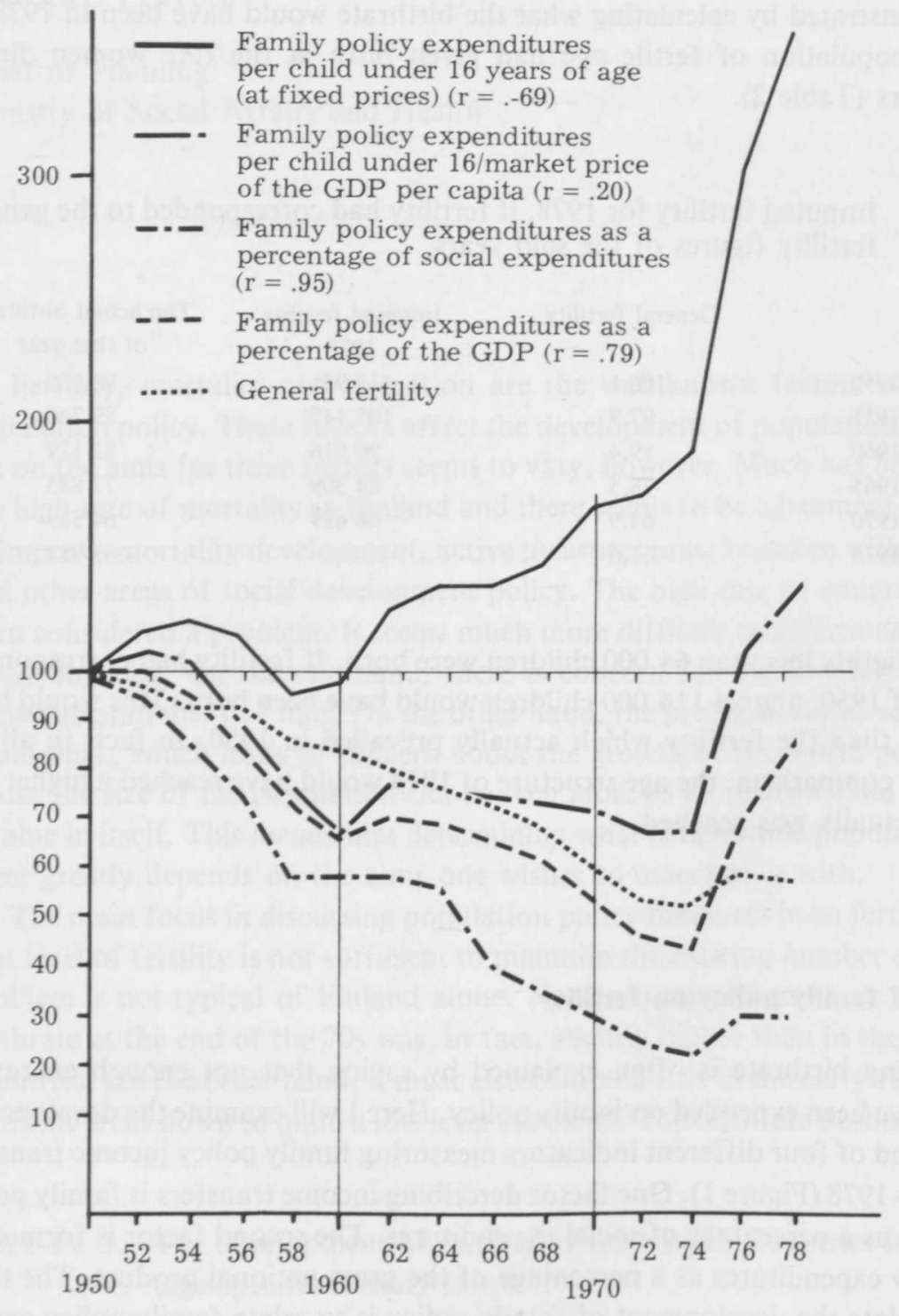

By choosing the appropriate series of figures we can prove either that family policy income transfers are strongly connected with fertility or we can prove the complete opposite, that these two have no connection whatever. The proportion family policy income transfers form of social expenditures »explains» the variation in fertility quite well. Part of this explanation is purely technical, of course, because 
the decline in fertility in itself diminishes the proportion of family policy expenditures. But given more careful consideration, it is in fact difficult to understand why this factor explains the variation in fertility better than the development of income transfers calculated per child. If one can assume that income transfers do affect fertility, then it would seem natural that the more money and services distributed per child the higher fertility will rise. But as the figure shows, their relation has been the opposite. It is interesting that when these expenditures per child are related to the development of the gross national product calculated per capita, the curve follows the development of fertility much more closely.

In analyzing the figure one should pay special attention to development in the 70s. One can see that general fertility turns from a declining trend to a rise in 1974 . At the same time all income transfer indicators also begin to rise. This could be interpreted to mean that exceptionally strong family policy measures are actually reflected in fertility figures. However, as fertility starts to decline again already in 1976, even though the income transfers continued to rise, it seems that these exceptionally strong measures are needed at regular intervals. As a whole the figure suggests that guaranteeing family policy income transfers is not in itself enough to raise the level of fertility. Income transfers should, in fact, be raised clearly more rapidly than the general rise in the level of prosperity.

It is in fact natural that family policy income transfers have a very limited effect. It is essentially a question of matters which are much harder to approach and which are also much harder to influence. In a way this is demonstrated by the correspondence which seems to prevail between the urban way of life and fertility (Table 3). It is well-known that as urbanization progresses fertility declines. Maybe

$\mathrm{T}$ a b l e 3. Correspondences between fertility and some factors. (correlation coefficients)

General fertility

The proportion of urban population

$-.97$

$-.97$

$-.89$

$-.28$

too little thought has been given to the fact that urbanization has at the same time also meant a general rise in prosperity and the level of income, which in itself has not raised fertility. Fertility has declined even though the income and prosperity level of young families is clearly higher than that of previous age classes. At the same time social security in general has improved, and thus the danger of unforeseen social risks has decreased. Here one can add that the relative position of young families has weakened. In fact a closer examination should be made of what this means and how it is connected to the decisions families make concerning family size. 


\section{The position of young families}

If we really want to affect fertility figures and raise them to a level corresponding to the complete renewal of the population, a deeper and - perhaps more honest study than now should be made of how family size is related to common life values, ways of living, lifestyles and life situations. The significance of this approach can perhaps be clarified, if for a moment we pause to imagine how, in a family with three small children, both parents could live according to the »hedono-narcissistic» values of our times, meaning that they actively use all the available services providing culture and entertainment, participate in civic activities and effectively ensure the development of their job and professional career and thus put into practice the upward moving trend in economic and consumer thinking. Isn't this possible only if the family employs home help on a continuous two-swing shift, week in week out. In view of employment this is a marvelous idea. This way we could easily employ half a million people as home help. The first problem that arises, however, is who will pay their wages (totalling $20-25$ billion marks). The economic view of young families on an upward moving spiral would require that the costs be paid for from common funds. This would raise taxation by one fourth. Families with children would end up paying one half of this increase. And who would take care of the children of the persons providing home help? We cannot assume that these people, in turn, be denied the opportunity to carry out the lifestyle and life values of our time.

\section{What can be done to raise fertility}

After this playful example, we can consider more seriously what actually can be done. For the sake of simplification we can perhaps divide the problem in two. The first approach is based on the idea that by further developing existing measures fertility can and should be raised. The other way to approach the problem is to try to construct a completely alternative family-centered lifestyle and estimate how realization of this lifestyle fits in with the rest of life in society.

On the whole the effects of existing measures are limited. Perhaps, if one is very optimistic, one might dare to assume that achieving a slight rise in fertility or maintaining the current level would require a substantial increase of the real value of family policy income transfers at 3-4 year intervals. In the between years the rise in income transfers should apparently correspond to the rise in earned income. This approach would evidently demand that the real value of family policy income transfers be doubled at 6-7 year intervals. No matter how financing is arranged a ceiling will naturally be reached in one way or another. One ceiling, a relative one, is the financial burden the child causes the family. According to some estimates the tripling or quadrupling of family policy income transfers would about cover the expenditures caused by a child. This figure is quite theoretical, however, because fami- 
ly policy income transfers are connected on various ways to the family's life circumstances and its life phases.

The other approach I mentioned was emphasizing a family-centered lifestyle. Here we would have to deal with job and sexual equality. More flexible arrangements of work and production for the father or the mother are evidently required in order to realize the demands made by family life. But obviously, before we start to develop individual measures, a revolution in values should take place. Families themselves should feel that family life is desirable, that it is a way of life that surpasses all other alternatives. Much more than we realize, this is a question of what we consider the purpose of a measure. Is the purpose of every family policy measure to increase the freedom of the parents and in a way to widen the possibilities for reaching out away from the home and the family. If the familycentered way of life is taken as a focus, each measure is adapted so that it serves the family as a whole, the family's ability to function and to be together. Evidently, this way of thinking should eventually spread to life in general: everywhere the family goes, the children can go also. However, I'd like to comment that it may be even more difficult to arrive at a situation where everywhere children and young people go, parents may go also.

Apparently in the society of the future, economic possibilities and possibilities for production will allow more flexibility than before. This is largely a question of what the ideals and values are according to which these possibilities are used. If there is a genuine desire to see that the population question and family policy are essential, there must also be a readiness to see the revolutionary change that is needed in society and in its values and ways of functioning, in order that we could live according to these values and ideals. 